Original Article

\title{
The effects of extracorporeal shock wave therapy on stroke patients with plantar fasciitis
}

\author{
Tae Gon Kim, MSc, PT ${ }^{1)}$, Sea Hyun Bae, PhD, PT ${ }^{2)}$, Gye Yeop Kim, PhD, OVD ${ }^{3)}$, \\ Kyung YoOn KIM, PhD, PT $^{3)^{*}}$ \\ 1) Department of Physical Therapy, Dongshin University, Republic of Korea \\ 2) Department of Physical Therapy, Cheongam College, Republic of Korea \\ 3) Department of Physical Therapy, College of Health and Welfare, Dongshin University: 252 \\ Daeho-dong, Naju-si, Chonnam 520-714, Republic of Korea
}

\begin{abstract}
Purpose] The purpose of this research was to analyze the efficacy of extracorporeal shock wave therapy for the treatment of stroke patients with plantar fasciitis. [Subjects and Methods] This study included 10 stroke patients diagnosed with plantar fasciitis who were administered 3 sessions of extracorporeal shock wave therapy per week. After the last session, they performed stretching exercises for their Achilles tendon and plantar fascia for $30 \mathrm{~min} /$ day, 5 times a week for 6 months. The following parameters were measured and compared prior to therapy, 6 weeks after therapy, and 6 months after therapy: thickness of the plantar fascia, using an ultrasonic imaging system; degree of spasticity, using a muscle tension measuring instrument; degree of pain, using the visual analogue scale; and gait ability, using the Functional Gait Assessment. [Results] Decreased plantar fascia thickness, spasticity, and pain and increased gait ability were noted after therapy. These changes were significantly greater at 6 months after therapy than at 6 weeks after therapy. [Conclusion] These results indicated that extracorporeal shock wave therapy reduced tension in the plantar fascia, relieving pain and improving gait ability in stroke patients.

Key words: Extracorporeal shock wave therapy, Plantar fascia, Gait
\end{abstract}

(This article was submitted Jul. 31, 2014, and was accepted Sep. 10, 2014)

\section{INTRODUCTION}

Stroke patients suffer from spontaneous muscle contraction and improper muscle activity and spasticity as a result of disability with respect to gait ability ${ }^{1)}$. In the case of paralysis of the ankle joint, spasticity paralysis is exhibited in the plantar flexor ${ }^{2}$. As a result, the heel cannot strike the ground, causing the stance phase to be shortened because only the forefoot can make contact with the ground ${ }^{3)}$.

The plantar fascia supports the center part of the foot and the articulationes metatarsophalangeae. It provides stability during the last stance phase and at the beginning of the swing phase ${ }^{4}$.

Stroke patients show asymmetric walking conditions brought forth by selective muscle use caused by spasticity and paralysis ${ }^{5)}$. This type of change in walking conditions can cause biomechanical problems and overload of pressure on both the paralyzed plantar fascia side and the normal side.

If heel impact is continuously repeated, especially under high muscle tension or unstable functioning conditions, it may put the plantar fascia, which maintains the arch of the

*Corresponding author. Kyung Yoon Kim (E-mail: redbead7@daum.net)

C2015 The Society of Physical Therapy Science. Published by IPEC Inc. This is an open-access article distributed under the terms of the Creative Commons Attribution Non-Commercial No Derivatives (by-ncnd) License $<$ http://creativecommons.org/licenses/by-nc-nd/3.0/>. feet and absorbs the impact caused by movement, at resk of micro-tears ${ }^{6}$. If excessive pressure is repeatedly applied to the plantar fascia, the attached calcaneus will be affected, causing infection and ultimately causing plantar fasciitis ${ }^{7)}$.

Recently, ultrasonography has been used to measure the thickness of the plantar fascia and examine plantar fasiitis ${ }^{8)}$. Wearing et al. ${ }^{9)}$ used ultrasonography and reported that the plantar fascia was thicker when there was pain in the heel while the body weight was being applied. Ogden et al. ${ }^{8)}$ and Rompe et al. ${ }^{10)}$ reported after numerous studies that a new type of therapy for plantar fasciitis, extracorporeal shock wave therapy (ESWT), showed positive therapy effects for spasticity. However, the evaluation of the effects was based mainly on the patients' subjective measurement of change in the degree of pain ${ }^{11,12)}$.

The MAS (Modified Ashworth Scale) is being clinically used to determine the degree of spasticity. However, the MAS is considered a subjective evaluation tool and is given little credibility, and the result value at medium degrees makes it difficult for distinguishing difference in the levels. Thus, it cannot detect small changes ${ }^{13)}$. Recently, the Myotonometer has been recommended based on its ability to produce useful values in measurement of the degree of spasticity ${ }^{14)}$.

So for physical therapists that are helping patients to walk, the information above is important and should be taken in to consideration. Many of these factors, however, are not taken into consideration in today's medical field, and most focus mainly on the alignment of the leg muscles, resistance training, sensory training, muscle tension training, 
etc., during gait training. The purpose of this research was to find out about the effects of ESWT on plantar fasciitis in stroke patients and to collect basic data on the structural changes and functions of the feet in stroke patients.

\section{SUBJECTS AND METHODS}

\section{Subjects}

The characteristics of the subjects in this research are shown in Table 1. The following research was performed on 10 stroke patients diagnosed with plantar fasciitis, and the conditions for selecting the candidates were as follows ${ }^{7,15-18)}$. patients diagnosed with hemiparalysis due to stroke who had been at the chronic stage for 6 months to 2 years but could walk on their own; patients who had been diagnosed by a rehabilitation expert as having plantar fasciitis on the paralyzed side based on an ultrasonic image diagnosis (ultrasonic image must have shown that the thickness of the plantar fascia was over $4 \mathrm{~mm}$ from the standard point of the calcaneus rim); patients with at least G1 plantar flexors of the ankle on the paralyzed side as, evaluated through the MAS; patients who did not have other foot injuries, tarsal tunnel syndrome, Achilles tendinitis, nerve entrapment syndrome, or any other symptoms in the foot that were causing pain; and patients who could understand the researchers commands and execute them. All subjects agreed voluntarily to participate in this research. The commencement of the research took place after the final administration of ESWT. After the final administration of ESWT, each subject performed stretching exercises for their Achilles tendon and plantar fascia for 30 minutes a day 5 times a week for a period of 6 months, and collection of data began with approval from the life ethics research society at Dongshin University (BM-001-01).

\section{Methods}

The ShockMaster 500 (APSUN Inc., GymnaUniphy, NV, Belgium) was used for the ESWT. Because the shock wave energy is lessened as it passes through tissues, ultrasonography (Accuvix V10, Samsung Medison, Seoul, South Korea) was used to observe the movement of the therapy areas in depth prior to ESWT so that only the exact area of the subjects would be treated. As in the Moon ${ }^{19}$ and Sohn et al. ${ }^{20)}$ methods, the subjects lay in a supine position without topical anesthesia and vertically at $15 \mathrm{~mm}$ depth 1,500 times, at $4 \mathrm{~Hz}, 0.089 \mathrm{~mJ} / \mathrm{mm}^{2}$ energy and are given 1 therapy per week for 3 weeks, at a bearable level of pain. After the therapy, the subjects were given 30 minutes of rest on a bed and then returned to their daily lives. During the 3-week therapy period, all exercise for improving plantar pressure were avoided. Achilles tendon stretching was performed by placing both arms against the wall, with the paralyzed leg stretched out to the back and then bending the front knee while standing up straight to stretch out the calf of the paralyzed leg. For the plantar fascia, the subject was be seated in a chair, put the paralyzed side's foot on top of the opposite knee, and then performed a dorsiflexion stretch for the plantar fascia. The Achilles tendon and plantar fascia stretching was executed for 6 months starting from the last day of ESWT ${ }^{21)}$.

In order to measure the thickness of the plantar fascia, an
Table 1. Clinical characteristics of subjects

\begin{tabular}{lc}
\hline Characteristics & Subjects $(\mathrm{n}=10)$ \\
\hline Gender (male/female) & $5 / 5$ \\
Affected side (left/right) & $5 / 5$ \\
Causes (infraction/hemorrhage) & $5 / 5$ \\
Age (years) & $64.10 \pm 4.01$ \\
Since onset (months) & $17.60 \pm 2.36$ \\
Height (cm) & $161.40 \pm 8.36$ \\
Weight $(\mathrm{kg})$ & $60.80 \pm 9.31$ \\
\hline
\end{tabular}

All data are expressed as means with the standard deviation $(\mathrm{M} \pm \mathrm{SD})$

ultrasonic imaging system with a 7.5 MHz linear transducer was used (Accuvix V10, Samsung Medison, Seoul, South Korea $)^{22}$. The position of the subjects for conducting measurements was as follows: the subject lay flat on the back with both feet extended so that the feet were placed right outside the edge of the bed. The thickness of the thickest area of the muscle area that connects the calcaneal tuberosity to the plantar fascia was scanned longitudinally. Also, we inspected for any conditions of micro-tears or calcification within the fascia.

A Myotonometer ${ }^{\circledR}$ (Neurogenic Technologies Inc.) was used to measure the level of tension of the medialis gastrocnemius. The strength levels measured by the cylinders were separated in to 8 levels $(0.25,0.75,1.00,1.25,1.5$, $1.75,2.00 \mathrm{~kg}$ ), and the levels were then converted into measurements in millimeters by displacement. The subsequent research used a median figure of $1.00 \mathrm{~kg}$.

To measure the subjective pain level of the plantar fascia, the Visual Analogue Scale (VAS) was used: 0 represented no pain, and 10 represented unbearable pain. The Subjects were given 30 seconds to mark the level of pain they were experiencing on the scale ${ }^{23}$.

The Functional Gait Assessment (FGA) was used to determine walking capabilities. It consists of 10 items, and each item is scored on a 4-point scale, from 0 to 3 . The least number of points possible for this assessment is 0 , while the highest number of points possible is 30 . A higher number of point indicates better walking ability. The intra- and interrater reliabilities for stroke patients were $\mathrm{r}=0.77$ and $\mathrm{r}=0.97$, respectively ${ }^{24,25)}$.

All assessments were conducted before the therapy, 6 weeks after the therapy, and 6 months after the therapy, and all measurements were repeated 3 times; the average of the 3 measurements was used.

All average and standard deviation data for the research were calculated with the SPSS for Windows, Version 12.0, statistical program. To determine the difference in the thickness of the plantar fascia, the degree of spasticity, degree of pain, and gait ability after ESWT and Achilles tendon and plantar fascia stretching, a repeated measure of ANOVA was conducted, and Bonferroni correction was used for post hoc examination. The selected level of statistical significance was $\mathrm{a}=0.05$. 
Table 2. Comparison of plantar fascia thickness, degree of spasticity, pain scale, and gait ability

\begin{tabular}{lccc}
\hline & Before Tx. & 6 weeks & \multicolumn{1}{c}{6 months } \\
\hline Plantar fascia thickness (mm) & $4.89 \pm 0.38$ & $4.46 \pm 0.31^{* * *}$ & $3.92 \pm 0.28^{* * *}$ \\
Spasticity (displacement) (mm) & $4.10 \pm 0.13$ & $3.89 \pm 0.13^{* * *}$ & $3.21 \pm 0.11^{* * *}$ \\
Pain scale (VAS) (score) & $6.50 \pm 0.97$ & $5.30 \pm 0.82^{* * *}$ & $3.80 \pm 0.78^{* * *}$ \\
Gait ability (FGA) (score) & $16.10 \pm 5.74$ & $19.40 \pm 5.44^{* * *}$ & $26.10 \pm 4.45^{* * *}$ \\
\hline
\end{tabular}

All data are expressed as means with the standard deviation $(\mathrm{M} \pm \mathrm{SD})$.

Repeated measures ANOVA was performed with respect to the differences in plantar fascia thickness, degree of spasticity, pain scale, and gait ability. The Bonferroni test was performed as a post hoc test $(* * * \mathrm{p}<0.001)$.

VAS: visual analogue scale; FGA: functional gait assessment

\section{RESULTS}

The thickness of the plantar fascia was $4.89 \pm 0.38 \mathrm{~mm}$ before the therapy, $4.46 \pm 0.31 \mathrm{~mm}$ six weeks after the therapy, and $3.92 \pm 0.28 \mathrm{~mm}$ after six months, and the degree of spasticity was $4.10 \pm 0.13 \mathrm{~mm}$ before the therapy, $3.89 \pm 0.13 \mathrm{~mm}$ six weeks after the therapy, and $3.21 \pm 0.11 \mathrm{~mm}$ six months after the therapy. The VAS score was $6.50 \pm 0.97$ before the therapy, $5.30 \pm 0.82$ six weeks after the therapy, and $3.80 \pm 0.78$ six months after the therapy. Walking ability was scored as $16.10 \pm 5.74$ before the therapy $19.40 \pm 5.44$ six weeks after the therapy, and $26.10 \pm 4.45$ six months after the therapy. All measurements showed noticeable changes between before the therapy, six weeks after the therapy, and six months after the therapy $(\mathrm{p}<0.001)$. Also, the difference in the results was much greater for six months after the therapy than for six weeks after the therapy (Table 2).

\section{DISCUSSION}

The plantar fascia begins at the calcaneus tubercle inner bump area, and it includes the thick center part and the weak parts on both sides ${ }^{26)}$. Based on histology, the extracellular matrix within the plantar fascia is composed of collagen and elastic fiber, and spasticity is caused by a change in alignment of the elastic fibers induced by overload of pressure $^{27)}$. While walking during the heel strike phase, loading response phase, push off phase, all play an important role in supporting the plantar arch of the plantar fascia ${ }^{26)}$. Any inflammation in the plantar fascia or any within the fascia area is called plantar fasciitis ${ }^{28)}$. An ultrasound imaging system is useful for examining plantar fasciitis and can be used to noninvasively, quickly, and easily determine the change in thickness of the plantar fascia ${ }^{17,29)}$. Soretino et al. ${ }^{17)}$ reported that the normal thickness of the plantar fascia is $4 \mathrm{~mm}$, while Tsai et al. reported that the normal plantar fascia and plantar fasciitis can be distinguished using $4 \mathrm{~mm}$ as a standard. For a proper swing toe-off while walking, the longitudinal arches of the feet must be higher, and the feet must be in a state of supination; based on this the windlass mechanism is considered important. The Windlass mechanism is a mechanism that ensures harmonious movement so that the foot can maintain stability and the longitudinal level of the muscle ligaments, tendons, and bon structure ${ }^{30)}$. Dorsiflexion of the big toe pulls the plantar fascia tight and brings the forefoot and the rearfoot close together, creating a short foot and by doing this, the foot is able to create momentum ${ }^{31)}$. However, if this mechanism is broken due to multiple sources of symptoms, the individual is unable to make an effective push off with the tip of the foot, changing the gait cycle and causing irregular walking patterns ${ }^{32}$. Stroke patients are able to recover and function properly and have the potential to return to their daily lives, while hemiparalyzed patients are able to recover $70 \%$ of their walking abilities ${ }^{33}$. However, stroke patients have difficulties walking due to pain caused by improper posture and inefficient movement conditions ${ }^{5)}$, selective decline of muscle control, and primitive common patterns, which is a common characteristic of stroke patients that affects the walking conditions ${ }^{32}$.

At the ankle joint, the plantar flexor shows signs of spasticity paralysis, and changes in the plantar flexor are common, causing difficulties in supporting the body weight ${ }^{33)}$. We suspect that these types of phases of the gait causes an overload of pressure on the paralyzed foot side that has an effect on the change in thickness of the plantar fascia. The ESWT, despite a variety of conservative therapies that do not result in an improvement in the symptoms, is being used widely as a replacement for surgery in treatment of plantar fasciitis $^{8,10)}$. The mechanism of action is not clear at this point; however, it has been shown that it improves revascularization boosts secretion of local growth factors, and accelerates the local distribution of stem cells, inducing the healing process in normal tissues ${ }^{34)}$ and one characteristic of a shock wave is that it causes a strong pressure change in matter with elasticity with the created pressure wave generating high mechanical strength and strong pressure ${ }^{35)}$.

The purpose of this research was to determine out the effects of ESWT on stroke patients with plantar fasciitis and how it affects the thickness of the plantar fascia, spasticity, degree of pain, and gait ability. The results of this research in stroke patients diagnosed with plantar fasciitis indicated that in both the short ( 6 weeks after therapy, $\mathrm{p}<0.001)$ and long terms ( 6 months after therapy $\mathrm{p}<0.001)$, there was a considerable decrease in the thickness of the plantar fascia, spasticity, and degree of pain, Also, the research showed that the change in thickness of the plantar fascia, spasticity, and degree of pain was considerably larger in the long term (6 months after therapy) than in the short term (6 weeks after therapy). The research results were in agreement with those of research conducted by Liang et al. ${ }^{36}$, who found that between 6 weeks and 24 weeks after ESWT, the plantar fascia stabilized and there was a decrease in the plantar fascia 
thickness.

When we compared our results with those of Pfeffer et al. ${ }^{37)}$, in which stretching of the Achilles tendon and plantar fascia took place, the decrease in thickness of the plantar fascia, coincided with the results of the present research. So in other words, although blood vessel contraction and a decrease in blood circulation in the plantar fascia continue in the long term, through ESWT, the conditions are improved by a physiological mechanism. Also, ESWT results in an increase in recruitment of local growth factors and stem cells that eliminates the plantar fasciitis condition and reorganizes the tissues of the fascia. Furthermore, application of ESWT to stroke patients with plantar fasciitis appeared to have a considerable affect on lowering the thickness of the plantar fascia, spasticity, and the degree of pain.

Meanwhile, the results of this research showed noticeable changes in gait abilities in both the short term ( 6 weeks after therapy, $\mathrm{p}<0.001)$ and long term (6 months after therapy $\mathrm{p}<0.001)$. This research also showed that the change in gait ability was considerably larger in the long term (6 months after therapy) than in the short term (6 weeks after therapy). From such results, we suggest that while walking, the paralyzed side of the subjects exhibited an incorrect stance phase that caused overloading of body weight onto the forefoot and increased tension in the plantar fascia, affecting their gait abilities.

These results indicate that application of ESWT to stroke patients with plantar fasciitis has a positive effect on the thickness of the plantar fascia, spasticity, degree of pain, and gait ability. So we can consider that ESWT helps in improving expansibility in the plantar fascia and spasticity and helps to relieve pain and enhance gait ability.

\section{REFERENCES}

1) Sharp SA, Brouwer BJ: Isokinetic strength training of the hemiparetic knee: effects on function and spasticity. Arch Phys Med Rehabil, 1997, 78: 1231-1236. [Medline] [CrossRef]

2) Gage JR: Gait analysis in cerebral palsy. New York: Mackeith Press, 1991

3) Norkin C: Gait analysis. In: O'Sullivan SB and Schmitz TJ, Physica Rehabilitation: Assessment and treatment, 3rd ed. Philadelphia: FA DAVIS 1994, pp167-191.

4) Baxter DE: The heel in sport. Clin Sports Med, 1994, 13: 683-693. [Medline]

5) Wall JC, Turnbull GI: Gait asymmetries in residual hemiplegia. Arch Phys Med Rehabil, 1986, 67: 550-553. [Medline]

6) Karabay N, Toros $\mathrm{T}$, Hurel C: Ultrasonographic evaluation in plantar fasciitis. J Foot Ankle Surg, 2007, 46: 442-446. [Medline] [CrossRef]

7) Roxas M: Plantar fasciitis: diagnosis and therapeutic considerations. Altern Med Rev, 2005, 10: 83-93. [Medline]

8) Ogden JA, Alvarez RG, Marlow M: Shockwave therapy for chronic proximal plantar fasciitis: a meta-analysis. Foot Ankle Int, 2002, 23: 301-308. [Medline]

9) Wearing SC, Smeathers JE, Sullivan PM, et al.: Plantar fasciitis: are pain and fascial thickness associated with arch shape and loading? Phys Ther, 2007, 87: 1002-1008. [Medline] [CrossRef]

10) Rompe JD, Schoellner C, Nafe B: Evaluation of low-energy extracorporeal shock-wave application for treatment of chronic plantar fasciitis. J Bone Joint Surg Am, 2002, 84-A: 335-341. [Medline]

11) Hammer DS, Rupp S, Kreutz A, et al.: Extracorporeal shockwave therapy (ESWT) in patients with chronic proximal plantar fasciitis. Foot Ankle Int, 2002, 23: 309-313. [Medline]

12) Böddeker R, Schäfer H, Haake M: Extracorporeal shockwave therapy
(ESWT) in the treatment of plantar fasciitis - a biometrical review. Clin Rheumatol, 2001, 20: 324-330. [Medline] [CrossRef]

13) Haas BM, Bergström E, Jamous A, et al.: The inter rater reliability of the original and of the modified Ashworth scale for the assessment of spasticity in patients with spinal cord injury. Spinal Cord, 1996, 34: 560-564. [Medline] [CrossRef]

14) Leonard CT, Brown JS, Price TR, et al.: Comparison of surface electromyography and myotonometric measurements during voluntary isometric contractions. J Electromyogr Kinesiol, 2004, 14: 709-714. [Medline] [CrossRef]

15) De Vera Barredo R, Menna D, Farris J: An evaluation of research evidence for selected physical therapy interventions for plantar fasciitis. J Phys Ther Sci, 2007, 19: 41-56. [CrossRef]

16) Bohannon RW, Larkin PA, Smith MB, et al.: Relationship between static muscle strength deficits and spasticity in stroke patients with hemiparesis. Phys Ther, 1987, 67: 1068-1071. [Medline]

17) Sorrentino F, Iovane A, Vetro A, et al.: Role of high-resolution ultrasound in guiding treatment of idiopathic plantar fasciitis with minimally invasive techniques. Radiol Med (Torino), 2008, 113: 486-495. [Medline] [CrossRef]

18) Tsai WC, Chiu MF, Wang CL, et al.: Ultrasound evaluation of plantar fasciitis. Scand J Rheumatol, 2000, 29: 255-259. [Medline] [CrossRef]

19) Moon SW: The effect of extracorporeal shock wave therapy on lower limb function and spasticity in stroke patients. Master's degree, 2013, 1-22.

20) Sohn MK, Cho KH, Kim YJ, et al.: Spasticity and electrophysiologic changes after extracorporeal shock wave therapy on gastrocnemius. Ann Rehabil Med, 2011, 35: 599-604. [Medline] [CrossRef]

21) Terada S, Miaki H, Uchiyama K, et al.: Effects of isokinetic passive exercise and isometric muscle contraction on passive stiffness. J Phys Ther Sci, 2013, 25: 1347-1352. [Medline] [CrossRef]

22) Baek IH, Kim BJ: The effects of horse riding simulation training on stroke patients' balance ability and abdominal muscle thickness changes. J Phys Ther Sci, 2014, 26: 1293-1296. [Medline] [CrossRef]

23) Lee JW, Kang JS, Park SJ, et al.: Effects of inter-electrode distance on delayed onset muscle soreness in microcurrent therapy. J Phys Ther Sci, 2013, 25: 1451-1454. [Medline] [CrossRef]

24) Thieme H, Ritschel C, Zange C: Reliability and validity of the functional gait assessment (German version) in subacute stroke patients. Arch Phys Med Rehabil, 2009, 90: 1565-1570. [Medline] [CrossRef]

25) Walker ML, Austin AG, Banke GM, et al.: Reference group data for the functional gait assessment. Phys Ther, 2007, 87: 1468-1477. [Medline] [CrossRef]

26) Brown C: A review of subcalcaneal heel pain and plantar fasciitis. Aust Fam Physician, 1996, 25: 875-881, 884-885. [Medline]

27) Buchbinder R, Ptasznik R, Gordon J, et al.: Ultrasound-guided extracorporeal shock wave therapy for plantar fasciitis: a randomized controlled trial. JAMA, 2002, 288: 1364-1372. [Medline] [CrossRef]

28) Snider MP, Clancy WG, McBeath AA: Plantar fascia release for chronic plantar fasciitis in runners. Am J Sports Med, 1983, 11: 215-219. [Medline] [CrossRef]

29) Hyer CF, Vancourt R, Block A: Evaluation of ultrasound-guided extracorporeal shock wave theraphy (ESWT) in the treatment of chronic plantar fasciitis. J Foot Ankle Surg, 2000, 29: 255-259.

30) Perry J: Gait analysis: normal and pathological function. New Jersey: SLACK, 1992, pp 73-78.

31) Hicks JH: The mechanics of the foot. II. The plantar aponeurosis and the arch. J Anat, 1954, 88: 25-30. [Medline]

32) Brandstater ME, de Bruin $H$, Gowland $C$, et al.: Hemiplegic gait: analysis of temporal variables. Arch Phys Med Rehabil, 1983, 64: 583-587. [Medline]

33) Perry J: The mechanics of walking in hemiplegia. Clin Orthop Relat Res, 1969, 63: 23-31. [Medline]

34) Hammer DS, Adam F, Kreutz A, et al.: Extracorporeal shock wave therapy (ESWT) in patients with chronic proximal plantar fasciitis: a 2-year follow-up. Foot Ankle Int, 2003, 24: 823-828. [Medline]

35) Thiel M: Application of shock waves in medicine. Clin Orthop Relat Res, 2001, (387): 18-21. [Medline] [CrossRef]

36) Liang HW, Wang TG, Chen WS, et al.: Thinner plantar fascia predicts decreased pain after extracorporeal shock wave therapy. Clin Orthop Relat Res, 2007, 460: 219-225. [Medline]

37) Pfeffer G, Bacchetti P, Deland J, et al.: Comparison of custom and prefabricated orthoses in the initial treatment of proximal plantar fasciitis. Foot Ankle Int, 1999, 20: 214-221. [Medline] [CrossRef] 